\title{
Decompressive hemicraniectomy for spontaneous intracerebral hemorrhage
}

\author{
Satoru Takeuchi, M.D., Kojiro Wada, M.D., Kimihiro Nagatani, M.D., \\ NaOki Otani, M.D., and Kentaro Mori, M.D. \\ Department of Neurosurgery, National Defense Medical College, Tokorozawa, Saitama, Japan
}

\begin{abstract}
Intracerebral hemorrhage $(\mathrm{ICH})$ is devastating, with high mortality rates, but its optimum management has not been fully established. Decompressive hemicraniectomy is a surgical procedure used to relieve the malignant elevation of intracranial pressure. The application of decompressive hemicraniectomy in patients with hemispheric ICH has been much less common, although several studies have shown the usefulness of this procedure for large hemispheric ICH. In this review, the present knowledge of the safety and efficacy of this procedure are evaluated. The authors conclude that decompressive hemicraniectomy with hematoma evacuation for large ICH might be a safe and effective procedure in patients with severely disturbed consciousness and large hematoma volume.

(http://thejns.org/doi/abs/10.3171/2013.2.FOCUS12424)
\end{abstract}

\author{
KeY WoRdS • decompressive hemicraniectomy • surgery • \\ intracerebral hemorrhage
}

$\mathrm{H}$ YPERTENSIVE ICH accounts for $10 \%-20 \%$ of strokes. ${ }^{4}$ Intracerebral hemorrhage can be devastating; mortality rates are high, ranging from $30 \%$ to $50 \%$ at 30 days, ,2,6,12 and many survivors remain severely disabled. The International Surgical Trial in Intracerebral Hemorrhage (STICH), a landmark trial involving over $1000 \mathrm{ICH}$ patients, showed that emergent surgical hematoma evacuation via craniotomy within 72 hours of onset failed to improve outcome compared with a policy of initial medical management. ${ }^{23}$ The STICH II study is currently enrolling patients to establish whether earlier hematoma evacuation in selected patients will improve outcome compared with conservative initial treatment. ${ }^{24}$ To date, the optimal management of ICH has not been definitively established.

Decompressive hemicraniectomy is a surgical procedure to relieve malignant elevation of ICP. It involves opening the skull and removing a bone flap to allow the edematous brain to swell outward, thus preventing in-

\footnotetext{
Abbreviations used in this paper: $\mathrm{DHC}=$ decompressive hemicraniectomy; GCS = Glasgow Coma Scale; GOS = Glasgow Outcome Scale; ICH = intracerebral hemorrhage; ICP = intracranial pressure; $\mathrm{IVH}=$ intraventricular hemorrhage; $\mathrm{mRS}=$ modified Rankin Scale; STICH = International Surgical Trial in Intracerebral Hemorrhage.
}

tracranial tissue shifts and life-threatening downward herniation. The procedure also has beneficial effects in reducing ICP and can contribute to improvements in cerebral compliance, cerebral oxygen supply, cerebral blood perfusion, and various abnormal CT signs., ${ }^{1,19,30}$ Decompressive hemicraniectomy has been used mainly for the treatment of severe traumatic brain injury, ${ }^{1,5,9,34,38}$ highgrade aneurysmal subarachnoid hemorrhage, ${ }^{8,14,27,31}$ and hemispheric cerebral infarction. . $^{3,15,17,35-37}$ The use of DHC to treat patients with hemispheric $\mathrm{ICH}$ has been much less common. However, DHC can improve outcome after experimental $\mathrm{ICH}$ in rats, ${ }^{22}$ and several clinical studies have demonstrated that this procedure is useful for large hemispheric ICHs. ${ }^{10,11,18,20,21,26,29,32,33}$

The present review summarizes our knowledge about DHC for the treatment of hemispheric ICH and discusses the safety and efficacy of this procedure.

\section{Methods}

A PubMed search for studies in the English language was performed using the key words "craniectomy" or "hemicraniectomy" in several combinations with the key words "hemorrhagic stroke" and "intracerebral hemorrhage." Series about cerebellar hemorrhage, hemorrhagic cerebral infarction, subarachnoid hemorrhage, and 


\section{S. Takeuchi et al.}

hemorrhage from known etiology (tumor, arteriovenous malformation, cavernoma, or cerebral sinus thrombosis) other than hypertension were excluded. We also decided to limit the analysis to series containing at least 5 cases treated surgically reported in papers that provided data about the outcomes. Favorable outcome was defined for purposes of this review as mRS scores of $0-2$ or the GOS categories good recovery or moderate disability. Poor outcome was defined as mRS scores of 3-6 or the GOS categories severe disability, vegetative state, or dead.

\section{Results}

A total of 9 studies were identified, reporting 226 cases in which DHC was performed for spontaneous hemispheric ICH. ${ }^{10,11,18,20,21,26,29,32,33}$ Seven of these studies reported 191 cases in which patients were treated with DHC with hematoma evacuation, ${ }^{10,18,20,21,26,32,33}$ and the other 2 studies reported 35 cases in which patients were treated with DHC without hematoma evacuation. ${ }^{11,29} \mathrm{Ta}-$ bles 1 and 2 summarize these studies.

\section{Decompressive Hemicraniectomy With Hematoma Evacuation}

The mean or median patient ages were reported in the range of 40-60 years. Preoperative consciousness was severely disturbed in many patients. Four studies reported frequencies of preoperative GCS scores of 8 or less $(\geq 8$ or $<8)$, and in these studies, at least $83 \%$ of patients (62 of 75) had a preoperative GCS score of 8 or less..$^{18,21,26,33}$ Four studies reported hematoma location in 147 patients. ${ }^{10,20,26,33}$ Hematoma location was the lobar region in $79(54 \%)$ of these 147 patients and the basal ganglia/thalamus in 69 patients $(47 \%)$. Four studies discussed IVH in 147 patients. ${ }^{10,20,26,33}$ Intraventricular hemorrhage was associated with ICH in 78 (53\%) of these 147 patients. Four studies measured hematoma volume in 79 patients..$^{20,26,32,33}$ Mean or median hematoma volume was relatively large $(>60 \mathrm{ml})$. All 7 studies reported the interval between hemorrhage onset and surgery, and 3 studies reported that the mean interval ranged from 8.3 to 22 hours. ${ }^{18,20,32}$ Four studies reported that $83(67 \%)$ of 124 patients underwent surgery within 24 hours after onset. $10,21,26,33$

Three studies reported the occurrence of complications in 86 patients, including hydrocephalus in 16 patients (19\%), intracranial hemorrhage in 3 patients $(3 \%)$, and infection in 3 patients (3\%). ${ }^{18,20,33}$ Clinical outcomes were assessed in various ways in all 7 studies. Two studies used the mRS, ${ }^{26,32}$ and 5 studies used the GOS..$^{10,18,20,21,33}$ However, 1 study of 5 patients reported only median $\mathrm{mRS},{ }^{32}$ and 1 patient left our previous study within the 1st month after DHC. ${ }^{33}$ Therefore, the outcomes of 185 cases were available for further analysis. Outcome was favorable in $75(41 \%)$ of 185 cases. Fifty-two (28\%) of the 185 patients died during various follow-up periods. In addition, 4 studies were case-control studies..$^{10,20,21,32}$ Three of these studies reported significant improvement in functional outcome or mortality compared with the control group (only hematoma evacuation), ${ }^{10,20,21}$ but one study reported no significant differences in outcome. ${ }^{32}$

\section{Decompressive Hemicraniectomy Without Hematoma Evacuation}

A total of 23 patients (age range 31-68 years) underwent only DHC for putamen hemorrhage. ${ }^{29}$ The GCS score was 8 or less in 7 patients $(30 \%)$. Intraventricular hemorrhage was observed in 6 patients. The hematoma volume was $30-60 \mathrm{ml}$ in 13 patients $(57 \%)$ and more than $60 \mathrm{ml}$ in 7 (30\%). Three patients underwent DHC within 6 hours after hemorrhage onset. Outcome was favorable in 15 patients (good recovery in 13 and moderate disability in 2). Three patients (13\%) died within 1 month of surgery.

Twelve patients (median age 48 years) underwent only DHC for hemorrhage in the basal ganglia (5 patients) or lobar (7 patients) region. ${ }^{11}$ The median GCS score was 8 . The median hematoma volume was $61 \mathrm{ml}$. The median interval between hemorrhage onset and surgery was 12 hours. Complications after DHC included intracranial hemorrhage in 2 patients $(17 \%)$ and infection in $1(8 \%)$. Outcome at 6 months was favorable in 4 patients $(33 \%)$. Three patients $(25 \%)$ died within 6 months of surgery. In addition, this study reported significant improvement in the functional outcome compared with the control group (only medical treatment).

\section{Discussion}

The optimum treatment for patients with spontaneous hemispheric ICH remains controversial. Outcomes have been disappointing for patients with large $\mathrm{ICH}$. Hematoma evacuation has been the most studied intervention for the surgical management of ICH, but hematoma evacuation alone may not be adequate to relieve intracranial hypertension. ${ }^{21,28}$ Hemorrhage triggers a series of negative pathogenic mechanisms soon after its onset, and this can result in the loss of cerebral autoregulation. ${ }^{21,28}$ Consequently, the ICP can increase again and reach pathological values within a few hours after hematoma evacuation. ${ }^{21,28}$ Decompressive hemicraniectomy has been considered as an option to resolve this problem.

\section{Decompressive Hemicraniectomy With Hematoma Evacuation}

This review identified a substantial cohort of patients who underwent DHC for spontaneous hemispheric ICH. Overall, we found that DHC was performed mainly in patients with GCS scores of 8 or less and large hematomas with a volume greater than $60 \mathrm{ml}$.

Among several postoperative complications, hydrocephalus was most frequent; it was observed in approximately $20 \%$ of patients undergoing DHC with hematoma evacuation. In addition, hemorrhagic or infectious complications occurred in $3 \%$ of patients who underwent DHC with hematoma evacuation. These findings were consistent with those in patients undergoing DHC for severe traumatic brain injury. 918,38 The development of hydrocephalus as a result of DHC has been well reported, whereas only one study has examined the risk factors for hydrocephalus after DHC with hematoma evacuation. We previously reported that the presence of IVH, the superior limit of the DHC, 
Decompressive hemicraniectomy for intracerebral hemorrhage

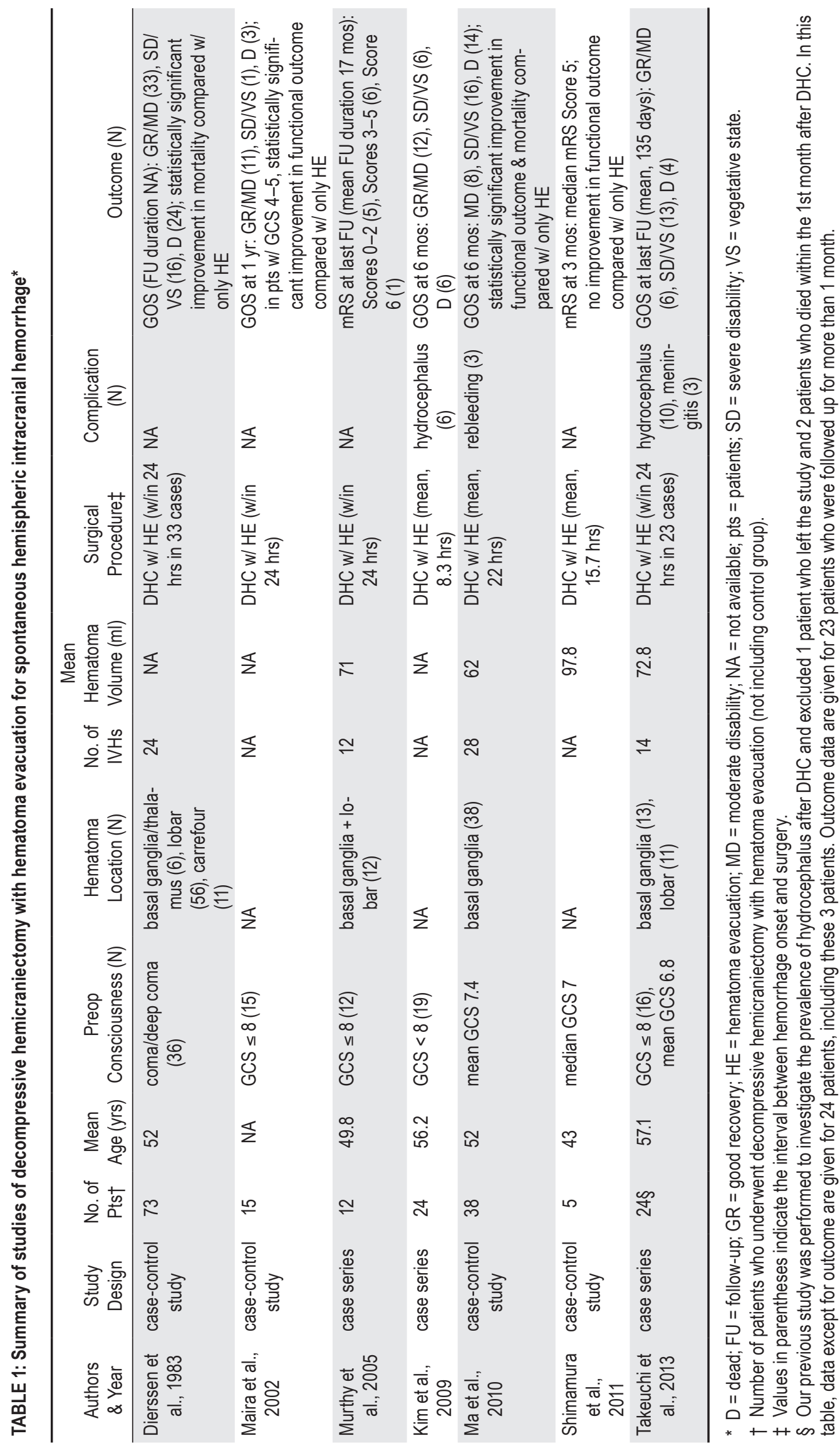




\section{S. Takeuchi et al.}

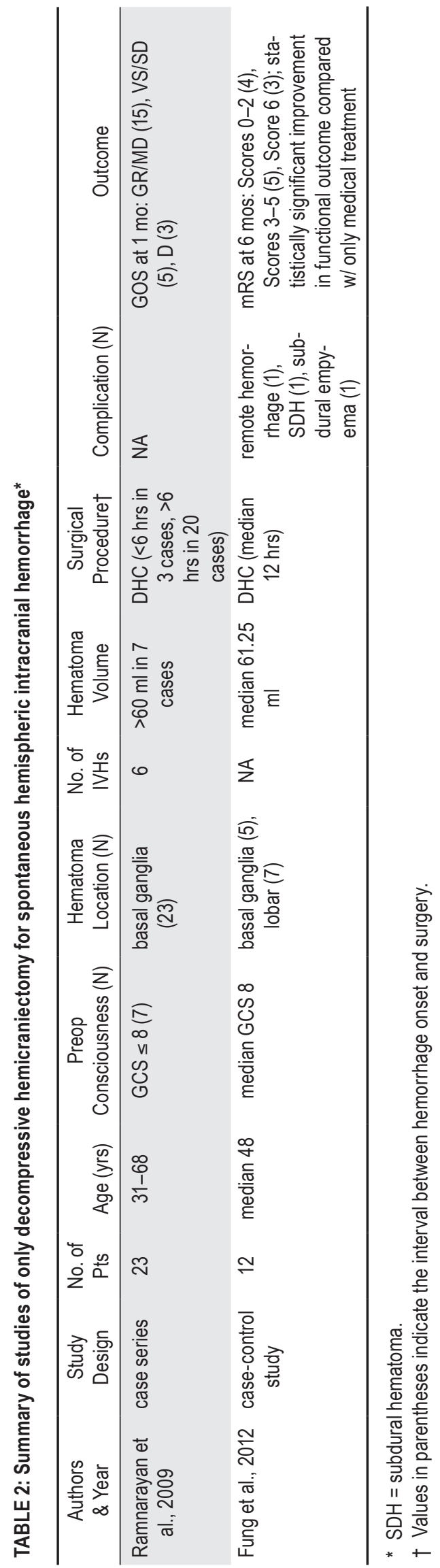

and the presence of meningitis might be causative factors for hydrocephalus after DHC, ${ }^{33}$ which is consistent with the findings in cases of DHC for traumatic brain injury. $5,9,16$

Preoperative consciousness and hematoma volume are the main predictive factors for outcome in ICH. In the study by Broderick et al., ${ }^{7}$ which included 142 patients with deep or lobar ICH, among whom $16 \%$ underwent hematoma evacuation, the patients with GCS scores of 8 or less and hematoma volume greater than $60 \mathrm{ml}$ had a mortality rate of $91 \%$. A meta-analysis by Gregson et al. ${ }^{13}$ found favorable outcomes in only $5 \%$ of patients with GCS scores of 8 or less and only $7 \%$ of patients with hematoma volumes of $80 \mathrm{ml}$ or greater. Although the present review found most patients had GCS scores of 8 or less and large hematoma volumes, a favorable outcome was achieved in $41 \%$ of cases and the overall mortality rate was $28 \%$, which indicates that $\mathrm{DHC}$ with hematoma evacuation might improve the outcomes of patients with such severe conditions. In fact, 3 of 4 case-control studies reported significant improvement in functional outcome or mortality compared with the control group (only hematoma evacuation), ${ }^{10,20,21}$ supporting this speculation. In addition, $42 \%$ of patients included in the STICH had associated IVH, and further detailed analysis of STICH revealed that the prognosis for patients with IVH is much worse than that for patients with only $\mathrm{ICH} .{ }^{23,24}$ In the current review, $53 \%$ of patients who underwent DHC with hematoma evacuation had associated IVH, indicating that $\mathrm{DHC}$ with hematoma evacuation might have some benefit even for patients with associated IVH.

In the STICH, the median time between hemorrhage onset and surgery was 30 hours in the early surgery group. ${ }^{23}$ Recent meta-analysis confirms that earlier surgery can be beneficial for ICH. ${ }^{13}$ In the present review, $67 \%$ of patients underwent DHC with hematoma evacuation within 24 hours after the hemorrhage onset, so early timing of surgery might have been one of the factors in the improvement of outcome. However, data on the timing of the procedure were not available for a large number of patients, so further studies are needed on this factor.

Minimally invasive surgery, including endoscopic surgery and stereotactic aspiration, have been used in the treatment of patients with ICH, with positive results suggesting the safety and efficacy of such techniques. ${ }^{39}$ The Minimally Invasive Surgery Plus Recombinant Tissue-Type Plasminogen Activator for ICH Evacuation (MISTIE) Phase II trial (NCT00224770) has recently reported significant reduction in perihematoma edema in patients who underwent successful hematoma evacuation after the MISTIE procedure. $^{25}$ The Intraoperative Stereotactic CT-Guided Endoscopic Surgery (ICES) arm of the trial is also in progress to determine the safety, feasibility, and effectiveness of endoscopic surgery.

However, meta-analysis of experiences with minimally invasive surgery has found that the candidates most likely to benefit from surgery have a GCS score of 9 or greater and hematoma volume between 25 and $40 \mathrm{ml},{ }^{39}$ conclusions that differ from those of our review. Therefore, whether minimally invasive surgery can have benefits for patients in even more severe condition remains debatable. We will reevaluate these results only after the 


\section{Decompressive hemicraniectomy for intracerebral hemorrhage}

ongoing trials are completed, but we presently consider that minimally invasive surgery has beneficial effects on outcome in patients with relatively mild disturbance of consciousness and small hematoma volume.

In addition to these limitations, the present review has some other limitations. We could not access detailed data on the size of the DHC, ICP, and extent of perihematoma edema. In addition, data on hematoma volume were not available for a large number of patients. Further studies are also needed on these factors.

Despite these limitations, the present findings suggest that DHC with hematoma evacuation is safe for the treatment of $\mathrm{ICH}$ and may reduce the mortality and improve the functional outcome, especially in patients with severely disturbed consciousness and large hematoma volume.

\section{Decompressive Hemicraniectomy Without Hematoma Evacuation}

Experimental DHC without hematoma evacuation in the rat $\mathrm{ICH}$ model can improve outcome, with earlier intervention of greater benefit, ${ }^{22}$ but whether DHC without hematoma evacuation is superior to hematoma evacuation without $\mathrm{DHC}$ or DHC with hematoma evacuation remains unclear.

In the series reported by Ramnarayan et al., ${ }^{29}$ only $30 \%$ of patients had GCS scores of 8 or less, and hematoma volumes were relatively small. Therefore, the resultant high rate of favorable outcomes $(65 \%)$ and low mortality rate $(13 \%)$ might be due to the relatively mild disease severity. On the other hand, in the recent series of Fung et al., ${ }^{11}$ most patients had severe preoperative conditions and relatively large ICH. Hemorrhagic or infectious complications occurred in $17 \%$ of patients and infection in $8 \%$, whereas relatively favorable outcome was obtained in $33 \%$, and the mortality rate was $25 \%$. However, the small sample does not allow us to analyze these complication rates and outcomes.

\section{Conclusions}

Decompressive hemicraniectomy with hematoma evacuation might be safe and effective for the treatment of large hemispheric ICH in selected patients. Further investigations including a prospective randomized trial are needed to confirm the safety and efficacy of DHC with hematoma evacuation for treatment of large ICH. The application of only DHC (DHC without hematoma evacuation) for ICH remains inconclusive because of the small number of reported patients. We suggest that selection of the optimal treatment protocol, including conservative therapy, minimally invasive surgery, conventional hematoma evacuation via craniotomy, and DHC with/without hematoma evacuation, should be based on the severity of the disease in individual patients.

\section{Disclosure}

The authors report no conflict of interest concerning the materials or methods used in this study or the findings specified in this paper.

Author contributions to the study and manuscript preparation include the following. Conception and design: Takeuchi. Acquisition of data: Takeuchi, Nagatani. Analysis and interpretation of data: Takeuchi. Drafting the article: Takeuchi. Critically revising the article: all authors. Study supervision: Mori.

\section{References}

1. Aarabi B, Hesdorffer DC, Ahn ES, Aresco C, Scalea TM, Eisenberg HM: Outcome following decompressive craniectomy for malignant swelling due to severe head injury. J Neurosurg 104:469-479, 2006

2. Anderson CS, Chakera TM, Stewart-Wynne EG, Jamrozik KD: Spectrum of primary intracerebral haemorrhage in Perth, Western Australia, 1989-90: incidence and outcome. J Neurol Neurosurg Psychiatry 57:936-940, 1994

3. Arnaout OM, Aoun SG, Batjer HH, Bendok BR: Decompressive hemicraniectomy after malignant middle cerebral artery infarction: rationale and controversies. Neurosurg Focus 30(6):E18, 2011

4. Bamford J, Sandercock P, Dennis M, Burn J, Warlow C: A prospective study of acute cerebrovascular disease in the community: the Oxfordshire Community Stroke Project-1981-86. 2. Incidence, case fatality rates and overall outcome at one year of cerebral infarction, primary intracerebral and subarachnoid haemorrhage. J Neurol Neurosurg Psychiatry 53:1622, 1990

5. Ban SP, Son YJ, Yang HJ, Chung YS, Lee SH, Han DH: Analysis of complications following decompressive craniectomy for traumatic brain injury. J Korean Neurosurg Soc 48:244-250, 2010

6. Broderick JP, Brott T, Tomsick T, Huster G, Miller R: The risk of subarachnoid and intracerebral hemorrhages in blacks as compared with whites. N Engl J Med 326:733-736, 1992

7. Broderick JP, Brott TG, Duldner JE, Tomsick T, Huster G: Volume of intracerebral hemorrhage. A powerful and easy-touse predictor of 30-day mortality. Stroke 24:987-993, 1993

8. D’Ambrosio AL, Sughrue ME, Yorgason JG, Mocco JD, Kreiter KT, Mayer SA, et al: Decompressive hemicraniectomy for poor-grade aneurysmal subarachnoid hemorrhage patients with associated intracerebral hemorrhage: clinical outcome and quality of life assessment. Neurosurgery 56:12-20, 2005

9. De Bonis P, Pompucci A, Mangiola A, Rigante L, Anile C: Post-traumatic hydrocephalus after decompressive craniectomy: an underestimated risk factor. J Neurotrauma 27:19651970, 2010

10. Dierssen G, Carda R, Coca JM: The influence of large decompressive craniectomy on the outcome of surgical treatment in spontaneous intracerebral haematomas. Acta Neurochir (Wien) 69:53-60, 1983

11. Fung C, Murek M, Z'Graggen WJ, Krähenbühl AK, Gautschi OP, Schucht P, et al: Decompressive hemicraniectomy in patients with supratentorial intracerebral hemorrhage. Stroke 43:3207-3211, 2012

12. Giroud M, Gras P, Chadan N, Beuriat P, Milan C, Arveux P, et al: Cerebral haemorrhage in a French prospective population study. J Neurol Neurosurg Psychiatry 54:595-598, 1991

13. Gregson BA, Broderick JP, Auer LM, Batjer H, Chen XC, Juvela $S$, et al: Individual patient data subgroup meta-analysis of surgery for spontaneous supratentorial intracerebral hemorrhage. Stroke 43:1496-1504, 2012

14. Güresir E, Raabe A, Setzer M, Vatter H, Gerlach R, Seifert V, et al: Decompressive hemicraniectomy in subarachnoid haemorrhage: the influence of infarction, haemorrhage and brain swelling. J Neurol Neurosurg Psychiatry 80:799-801, 2009

15. Hofmeijer J, Kappelle LJ, Algra A, Amelink GJ, van Gijn J, van der Worp HB: Surgical decompression for space-occupying cerebral infarction (the Hemicraniectomy After Middle Cerebral Artery infarction with Life-threatening Edema Trial [HAMLET]): a multicentre, open, randomised trial. Lancet Neurol 8:326-333, 2009 
16. Jiao QF, Liu Z, Li S, Zhou LX, Li SZ, Tian W, et al: Influencing factors for posttraumatic hydrocephalus in patients suffering from severe traumatic brain injuries. Chin J Traumatol 10:159-162, 2007

17. Jüttler E, Schwab S, Schmiedek P, Unterberg A, Hennerici M, Woitzik J, et al: Decompressive Surgery for the Treatment of Malignant Infarction of the Middle Cerebral Artery (DESTINY): a randomized, controlled trial. Stroke 38:2518-2525, 2007

18. Kim KT, Park JK, Kang SG, Cho KS, Yoo DS, Jang DK, et al: Comparison of the effect of decompressive craniectomy on different neurosurgical diseases. Acta Neurochir (Wien) 151:21-30, 2009

19. Kontopoulos V, Foroglou N, Patsalas J, Magras J, Foroglou G, Yiannakou-Pephtoulidou M, et al: Decompressive craniectomy for the management of patients with refractory hypertension: should it be reconsidered? Acta Neurochir (Wien) 144:791-796, 2002

20. Ma L, Liu WG, Sheng HS, Fan J, Hu WW, Chen JS: Decompressive craniectomy in addition to hematoma evacuation improves mortality of patients with spontaneous basal ganglia hemorrhage. J Stroke Cerebrovasc Dis 19:294-298, 2010

21. Maira G, Anile C, Colosimo C, Rossi GF: Surgical treatment of primary supratentorial intracerebral hemorrhage in stuporous and comatose patients. Neurol Res 24:54-60, 2002

22. Marinkovic I, Strbian D, Pedrono E, Vekovischeva OY, Shekhar S, Durukan A, et al: Decompressive craniectomy for intracerebral hemorrhage. Neurosurgery 65:780-786, 2009

23. Mendelow AD, Gregson BA, Fernandes HM, Murray GD, Teasdale GM, Hope DT, et al: Early surgery versus initial conservative treatment in patients with spontaneous supratentorial intracerebral haematomas in the International Surgical Trial in Intracerebral Haemorrhage (STICH): a randomised trial. Lancet 365:387-397, 2005

24. Mendelow AD, Gregson BA, Mitchell PM, Murray GD, Rowan EN, Gholkar AR: Surgical trial in lobar intracerebral haemorrhage (STICH II) protocol. Trials 12:124, 2011

25. Mould WA, Carhuapoma JR, Muschelli J, Lane K, Morgan TC McBee NA, et al: Minimally invasive surgery plus recombinant tissue-type plasminogen activator for intracerebral hemorrhage evacuation decreases perihematomal edema. Stroke 44:627634, 2013

26. Murthy JM, Chowdary GV, Murthy TV, Bhasha PS, Naryanan TJ: Decompressive craniectomy with clot evacuation in large hemispheric hypertensive intracerebral hemorrhage. Neurocrit Care 2:258-262, 2005

27. Otani N, Takasato Y, Masaoka H, Hayakawa T, Yoshino Y, Yatsushige H, et al: Surgical outcome following decompressive craniectomy for poor-grade aneurysmal subarachnoid hemorrhage in patients with associated massive intracerebral or Sylvian hematomas. Cerebrovasc Dis 26:612-617, 2008

28. Papo I, Janny P, Caruselli G, Colnet G, Luongo A: Intracranial pressure time course in primary intracerebral hemorrhage. Neurosurgery 4:504-511, 1979

29. Ramnarayan R, Anto D, Anilkumar TV, Nayar R: Decom- pressive hemicraniectomy in large putaminal hematomas: an Indian experience. J Stroke Cerebrovasc Dis 18:1-10, 2009

30. Schaller B, Graf R, Sanada Y, Rosner G, Wienhard K, Heiss WD: Hemodynamic and metabolic effects of decompressive hemicraniectomy in normal brain. An experimental PET study in cats. Brain Res 982:31-37, 2003

31. Schirmer CM, Hoit DA, Malek AM: Decompressive hemicraniectomy for the treatment of intractable intracranial hypertension after aneurysmal subarachnoid hemorrhage. Stroke 38:987-992, 2007

32. Shimamura N, Munakata A, Naraoka M, Nakano T, Ohkuma $\mathrm{H}$ : Decompressive hemi-craniectomy is not necessary to rescue supratentorial hypertensive intracerebral hemorrhage patients: consecutive single-center experience. Acta Neurochir Suppl 111:415-419, 2011

33. Takeuchi S, Nawashiro H, Wada K, Takasato Y, Masaoka H, Hayakawa T, et al: Ventriculomegaly after decompressive craniectomy with hematoma evacuation for large hemispheric hypertensive intracerebral hemorrhage. Clin Neurol Neurosurg 115:317-322, 2013

34. Takeuchi S, Takasato Y, Suzuki G, Maeda T, Masaoka H, Hayakawa T, et al: Postoperative computed tomography after surgery for head trauma. J Trauma Acute Care Surg 73: 1254-1260, 2012

35. Takeuchi S, Wada K, Nawashiro H, Arimoto H, Ohkawa H, Masaoka H, et al: Decompressive craniectomy after intravenous tissue plasminogen activator administration for stroke. Clin Neurol Neurosurg 114:1312-1315, 2012

36. Vahedi K, Hofmeijer J, Juettler E, Vicaut E, George B, Algra $\mathrm{A}$, et al: Early decompressive surgery in malignant infarction of the middle cerebral artery: a pooled analysis of three randomised controlled trials. Lancet Neurol 6:215-222, 2007

37. Vahedi K, Vicaut E, Mateo J, Kurtz A, Orabi M, Guichard JP, et al: Sequential-design, multicenter, randomized, controlled trial of early decompressive craniectomy in malignant middle cerebral artery infarction (DECIMAL Trial). Stroke 38:2506-2517, 2007

38. Yang XF, Wen L, Shen F, Li G, Lou R, Liu WG, et al: Surgical complications secondary to decompressive craniectomy in patients with a head injury: a series of 108 consecutive cases. Acta Neurochir (Wien) 150:1241-1248, 2008

39. Zhou X, Chen J, Li Q, Ren G, Yao G, Liu M, et al: Minimally invasive surgery for spontaneous supratentorial intracerebral hemorrhage: a meta-analysis of randomized controlled trials. Stroke 43:2923-2930, 2012

Manuscript submitted December 29, 2012.

Accepted February 27, 2013.

Please include this information when citing this paper: DOI: 10.3171/2013.2.FOCUS12424.

Address correspondence to: Satoru Takeuchi, M.D., Department of Neurosurgery, National Defense Medical College, 3-2 Namiki, Tokorozawa, Saitama 359-8513, Japan. email: s.takeuchi@room. ocn.ne.jp. 